\title{
Universiteit
}

Leiden

The Netherlands

\section{Monoclonal proteinaemia and solid tumours}

Schaar, C.G.; Snijder, S.; Oostindier, M.J.; Rosendaal, F.R.; Willemze, R.; Kluin-Nelemans, J.C.

\section{Citation}

Schaar, C. G., Snijder, S., Oostindier, M. J., Rosendaal, F. R., Willemze, R., \& KluinNelemans, J. C. (2004). Monoclonal proteinaemia and solid tumours. European Journal of Cancer, 40(10), 1539-1544. Retrieved from https://hdl.handle.net/1887/5087

Version: $\quad$ Not Applicable (or Unknown)

License:

Downloaded from: https://hdl.handle.net/1887/5087

Note: To cite this publication please use the final published version (if applicable). 


\title{
Monoclonal proteinaemia and solid tumours
}

\author{
C.G. Schaar ${ }^{\text {a }}$, S. Snijder ${ }^{\text {b }}$, M.J. Oostindiër ${ }^{b}$, F.R. Rosendaal ${ }^{a, c}$, \\ R. Willemze ${ }^{\text {a }}$, J.C. Kluin-Nelemans ${ }^{\text {d,* }}$ \\ ${ }^{\text {a }}$ Department of Hematology, Leiden University Medical Center, Leiden, The Netherlands \\ ${ }^{\mathrm{b}}$ Comprehensive Cancer Center West, Leiden, The Netherlands \\ ${ }^{\mathrm{c}}$ Department of Clinical Epidemiology, Leiden University Medical Center, The Netherlands \\ ${ }^{\mathrm{d}}$ Department of Hematology, Groningen University Hospital, P.O. Box 30001, 9700 RB Groningen, The Netherlands \\ Received 14 November 2003; accepted 25 November 2003 \\ Available online 19 May 2004
}

\begin{abstract}
A higher prevalence of solid tumours in patients with M(onoclonal) proteinaemia without a co-existing haematological malignancy has been reported. We investigated this association by linking a population-based registry of patients with newly diagnosed M-proteinaemia $(n=1464)$ with the Regional Cancer Registry. Patients were followed for a median of 7.4 years for those still alive. In total $167(11 \%)$ patients with 173 solid tumours were compared with 861 patients with 'M-proteinaemia only' (without a haematological malignancy). The M-protein isotype or level or clinical parameters did not differ between the groups. M-protein isotype was not associated with a specific tumour type. Standardised Morbidity Ratios (SMR) for nearly all solid tumours were elevated in the year of the M-protein discovery, but the excess risk disappeared during follow-up suggesting selection through diagnostic investigations rather than a causal role. In this large series of patients with both newly diagnosed M-proteinaemia and a solid tumour no relationship could be established.
\end{abstract}

(C) 2004 Elsevier Ltd. All rights reserved.

Keywords: M(onoclonal) protein; M(onoclonal) proteinaemia; Paraprotein; Solid tumour; Standardised morbidity ratio (SMR)

\section{Introduction}

For many decades, it has been assumed that in patients with monoclonal (M)-proteinaemia and without any evidence of a co-existing haematological malignancy, the prevalence of solid tumours is increased suggestive of a causal relationship [1-8]. Further analysis of this relationship could determine more exactly the incidence of this phenomenon in patients with a solid tumour and vice versa, thereby establishing the relevance of screening in cases of M-proteinaemia. To this end we linked a Dutch population-based M-protein database $[9,10]$ to the regional cancer registry, and compared solid tumour M-protein patients with other groups in order to try to establish a time relationship between both diagnoses.

\footnotetext{
${ }^{*}$ Corresponding author. Tel.: +31-50-3612354; fax: +31-50-3614862.

E-mail address: j.c.kluin-nelemans@int.azg.nl (J.C. Kluin-Nelemans).
}

\section{Patients and methods}

\subsection{Patient population}

From 1991 until 1993, a population-based registry on M-proteinaemia was set up in the region of the Comprehensive Cancer Center West (CCCW), a geographical area with 1.6 million inhabitants. Clinical chemists, internists, haematologists, pathologists and other physicians reported all patients with newly diagnosed M-proteinaemia or multiple myeloma in the CCCW area. Information on patients characteristics, laboratory test results, and results of bone marrow examinations and skeletal X-rays were documented. The M-proteinrelated diagnosis, co-morbidity and therapy were recorded. Follow-up was done annually. At follow-up, clinical data, any evolution into a haematological malignancy, appearance of any solid tumour, M-protein levels and other relevant laboratory tests were collected from the patients' hospital charts or from the general 
physician. In total, 1464 patients have been registered. The setup and contents of this registry have been described previously in $[9,10]$.

\subsection{Diagnostic criteria for monoclonal proteinaemia and solid tumours}

M-proteins were detected either by agarose or by cellulose acetate electrophoresis, depending on the method used in the various hospitals involved. For inclusion in the registry, each M-protein had to be confirmed by immunotyping (immunofixation). The presence of a solid tumour preferably had to be confirmed by histology, otherwise a clinical diagnosis had to be based on at least radiological evidence of a tumour. Cancer sites were grouped according to the World Health Organization's International Classification of Diseases for Oncology (ICD-O) [11].

\subsection{Linkage to the regional cancer registry}

For verification and to ensure the completeness of our data on solid tumours, the database was linked to the regional database of the Netherlands Regional Cancer Registry [12]. In this cancer registry, all patients with newly diagnosed malignancies living in the CCCW region reported by the pathology laboratories are entered. The date of the cytological or histological confirmation constitutes the date of diagnosis. In addition, all hospitals employ a separate registry of the discharge diagnoses. For the present study, patient data were linked if the name, gender and date of birth were identical in both databases to exclude the probability of false-positive or false-negative linkages.

\subsection{Solid tumour prevalence and incidence analysis}

Follow-up started at registration (between 1991 and 1993) and is still ongoing. For the solid cancer linkage study, complete coverage with the Regional Cancer Registry was guaranteed until January 1st 1998. Endpoints were the development of a (haematological) malignancy or death, and patients still alive were censored for all other events on January 1st 2002. First, the prevalence of a solid tumour at first diagnosis was calculated. Patients were diagnosed with a M-protein-related solid tumour if the tumour was diagnosed within the timeframe of two years, one year preceding or following the discovery of the M-protein. Thus, all malignancies that could be associated with the M-protein, but were not present anymore due to treatment were included, as well as any asymptomatic multiple myeloma (MM), other haematological malignancies or solid tumours that developed later on. In cases of a simultaneous haematological malignancy or solid tumour during this period, the M-protein was considered to be associated with the former and not with the solid tumour.

Secondly, Standardised Morbidity Ratios (SMR) for the most prevalent tumours were determined for the period between registration (1991-1993) until January 1, 1998. Patients with newly diagnosed M-proteinaemia were at risk until the diagnosis of a solid tumour, multiple myeloma, other haematological malignancy was made or until they died. Multiplication of person-years under observation by the age-, gender-, and periodspecific incidence rates yielded the number of solid tumours expected in the M-protein cohort if they experienced the same risk as was prevalent in the region of the CCCW. With this method, standardised incidence rates between patient and reference group were compared (indirect standardisation) and expressed as the ratio of the incidence rates (SMR), which may be viewed as a relative risk. Confidence limits for the SMR were based on a Poisson distribution for the observed number of deaths [13].

\subsection{Statistical methods}

Statistical methods to compare the 'M-proteinaemia Only' versus 'Solid tumour group' included MannWhitney's test and in the case of a case-control design, the chi-square test when appropriate. Analyses were performed using Statistical Package for the Social Sciences (SPSS) version 10. Data were entered in the database using SPSS Data Entry version 2 (both SPSS Inc. Chicago, IL, USA).

\section{Results}

\subsection{Prevalence of solid tumours at first diagnosis of M-proteinaemia}

The database consisted of 1464 patients with an initial diagnosis of M-proteinaemia. The frequency of newly discovered cases was $31 / 100,000$ inhabitants and $189 / 100,000$ for people above 70 years of age [9]. In 271 patients, a diagnosis of multiple myeloma was made, in 164 another haematological malignancy was diagnosed, but in the large majority no explanation was found (provisional [9] or definite monoclonal gammopathy of unknown significance, MGUS), (Table 1).

In total, 173 solid tumours without any evidence of multiple myeloma or other haematological malignancy were diagnosed in $167(11 \%)$ patients. The types of tumour found are depicted in Fig. 1. Nearly all tumours ( $n=167 ; 97 \%$ ) were (adeno)carcinomas, the other six malignancies consisted of melanomas $(n=4)$, leiomyosarcoma $(n=1)$ and sarcoma $(n=1)$. 
Table 1

Clinical characteristics in all diagnostic groups with M-proteinaemia

\begin{tabular}{|c|c|c|c|c|c|}
\hline & $\begin{array}{l}\text { Monoclonal proteinaemia } \\
\text { only/MGUS }\end{array}$ & Solid tumour & $P$-value & Multiple myeloma ${ }^{a}$ & $\begin{array}{l}\text { Other haematological } \\
\text { malignancies }{ }^{b}\end{array}$ \\
\hline Number $(\%)$ & $861(59)$ & $167(11)$ & & 271 (19) & $165(11)$ \\
\hline Gender M (\%) & $423(49)$ & $103(62)$ & 0.004 & $138(51)$ & $96(58)$ \\
\hline $\mathrm{F}(\%)$ & $438(51)$ & $64(38)$ & & $133(49)$ & $69(42)$ \\
\hline $\begin{array}{l}\text { Median age } \\
\quad \text { (range, years) }\end{array}$ & $73(17-103)$ & 75 (37-95) & 0.05 & $71(28-93)$ & $72(21-94)$ \\
\hline $\mathrm{M}$ & $72(20-103)$ & 75 (37-95) & 0.03 & $69(28-89)$ & $70(20-89)$ \\
\hline $\mathrm{F}$ & $75(17-98)$ & $76(47-92)$ & 0.91 & $72(40-93)$ & $73(25-94)$ \\
\hline \multicolumn{6}{|l|}{$\begin{array}{l}\text { M-protein type } \\
\text { and level }(\mathrm{g} / \mathrm{l})\end{array}$} \\
\hline $\operatorname{IgG}(\%)$ & $618(72)$ & $29(76)$ & 0.45 & $155(57)$ & $75(46)$ \\
\hline Median (range) & $10(1-30)$ & $10.5(<1-85)$ & & $32.5(6-117)$ & $12.3(<1-34)$ \\
\hline $\operatorname{IgA}(\%)$ & $80(9)$ & $10(6)$ & 0.71 & $75(28)$ & $5(3)$ \\
\hline Median (range) & $8.4(4-31)$ & $10(2-47)$ & & $28.1(5-81)$ & $15.6(2-25)$ \\
\hline $\operatorname{IgM}(\%)$ & $159(19)$ & $30(18)$ & 0.19 & $4(2)$ & $81(49)$ \\
\hline Median (range) & $7(1-21)$ & $10(<1-30)$ & & $22(2-57)$ & $13.8(2-110)$ \\
\hline
\end{tabular}

In the patient with prostate carcinoma, two haematological malignancies were observed: chronic lymphocytic leukaemia (CLL) and Hodgkin's lymphoma.

M, male; F, female; MGUS, monoclonal gammopathy of unknown significance.

${ }^{a}$ In five patients, a solid tumour was present (carcinoma of lung, breast, thyroid, ovary and unknown primary site).

${ }^{\mathrm{b}}$ In eight patients, a solid tumour was present (melanoma, carcinoma of unknown primary site, bladder, prostate, colon, larynx, skin and liver).

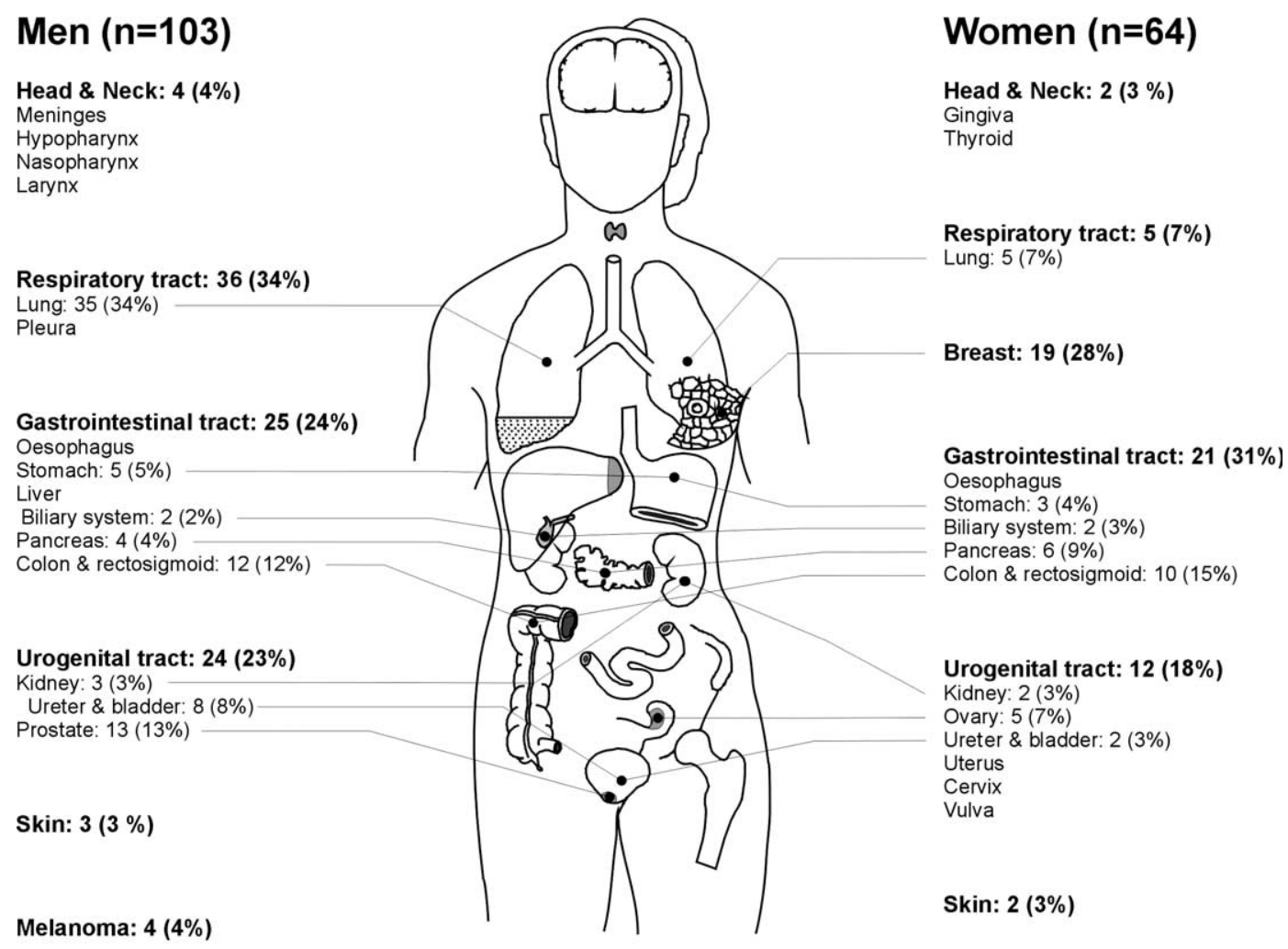

Unknown primary: $9(9 \%)$

Unknown primary: $7(10 \%)$

Fig. 1. Distribution of solid tumours and M-proteinaemia. Two tumours were diagnosed in six patients: bilateral breast (2), breast + pancreas, breast + colon leiomyosarcoma, squamous skin + melanoma, pancreas + gingiva. No percentage between brackets means only one tumour found. Modified from [19]. 


\subsection{Solid tumour and M-protein isotype}

To study whether specific tumour types were related to specific M-protein isotypes, we selected patients with one the six most frequently occurring solid tumours, lung $(n=40)$, colon $(n=21)$, breast $(n=15)$, prostate $(n=13)$, ureter and bladder $(n=10)$ and pancreas $(n=9)$. In all, the IgG isotype predominated $(60-85 \%)$, followed by $\operatorname{IgM}(7-30 \%)$ and $\operatorname{IgA}(0-10 \%)$. No clear preferential M-protein types were seen within the specific tumour groups.

\section{3. 'Solid tumour group' versus 'M-proteinaemia only group/MGUS'}

To study whether patients with M-proteinaemia and a solid tumour (i.e. "Solid tumour Group") had specific characteristics in demographics or M-protein isotype and levels, we compared this group with the patients without any malignancy (Table 1). In the tumour group, male gender predominated. In addition, small, but significant, differences in age were seen. The distribution of M-protein isotypes and levels was identical with most patients expressing a median of approximately $10 \mathrm{~g} / \mathrm{l}$ $\mathrm{IgG}$ monoclonal proteinaemia.

\subsection{Response of the M-protein on cancer treatment}

When M-proteins are causally related to a solid tumour, one would expect to find an increase of the M-protein levels during tumour progression and a decrease after tumour disappearance. In the Solid tumour group, 64 out of 167 patients died within one year after the detection of the M-protein leaving 103 patients with follow-up data. In 25 patients (median follow-up 37 months, range 3-95 months) the Mprotein was measured at least once after the first detection and therapy (if any) for the solid tumour. Since in four patients a haematological malignancy developed (see Section 3.5), a relationship (rising or lowering of the M-protein in correspondence with the progression or decrease of the tumour) could be studied only in 21 patients. In this small group of patients, no convincing relationship was seen between the behaviour of the solid tumour and M-protein levels (data not shown).

\subsection{Follow-up since entry in the M-protein database}

During follow up (last analysis 1-1-2002) a new solid tumour was detected in 23 patients in addition to those already diagnosed in the 167 patients. All of these tumours occurred in the period 1992-1998 (see Table 2). In the years thereafter, no additional solid tumours were found. Out of the 167 patients in whom a solid tumour was diagnosed simultaneously with the M-protein, three patients developed multiple myeloma (14, 56 and 65 months after the detection of the M-protein) and one patient developed a non-Hodgkin's lymphoma (NHL) (28 months after the detection of the M-protein).

For comparison, in the Monoclonal proteinaemia only/MGUS group, 28 developed multiple myeloma, and another 17 developed a haematological malignancies, consisting of a NHL $(n=12)$, myelodysplastic syndrome or acute myeloid leukaemia $(n=3)$ or myeloproliferative disease $(n=2)$.

Table 2

Standardised morbidity ratios (SMR) for the most prevalent solid tumours in the year of discovery of the M-protein and the years after

\begin{tabular}{|c|c|c|c|c|c|c|c|c|}
\hline \multirow{2}{*}{$\begin{array}{l}\text { Solid tumour (all (adeno) } \\
\text { carcinomas) }\end{array}$} & \multicolumn{4}{|c|}{ Year of M-protein discovery (1991-1993) } & \multicolumn{4}{|c|}{ Follow-up (1992-1998) } \\
\hline & $\begin{array}{l}\text { Observed } \\
\text { number }\end{array}$ & $\begin{array}{l}\text { Expected } \\
\text { number }\end{array}$ & SMR & $\begin{array}{l}95 \% \text { Confidence } \\
\text { interval }\end{array}$ & $\begin{array}{l}\text { Observed } \\
\text { number }\end{array}$ & $\begin{array}{l}\text { Expected } \\
\text { number }\end{array}$ & SMR & $\begin{array}{l}95 \% \text { Confidence } \\
\text { interval }\end{array}$ \\
\hline \multicolumn{9}{|l|}{ Men } \\
\hline Lung & 19 & 0.9 & 21.1 & $12.5-31.9$ & 5 & 4.1 & 1.2 & $0.4-2.6$ \\
\hline Colon and rectosigmoid & 4 & 0.4 & 10 & $2.5-22.5$ & 1 & 1.7 & 0.6 & $0-2.4$ \\
\hline Prostate & 5 & 0.9 & 5.6 & $1.7-11.6$ & 3 & 4.5 & 0.7 & $0.2-1.7$ \\
\hline Unknown primary & 5 & 0.2 & 25 & $7.6-52.4$ & 2 & 0.8 & 2.5 & $0.2-7.3$ \\
\hline Pancreas & 1 & 0.1 & 10 & $0-40$ & 0 & 0.25 & 0 & $0-4$ \\
\hline Stomach & 2 & 0.3 & 6.7 & $0.6-19.4$ & 0 & 0.8 & 0 & $0-1.3$ \\
\hline Bladder & 3 & 0.2 & 15 & $2.7-37.3$ & 1 & 1.0 & 1 & $0-4.0$ \\
\hline \multicolumn{9}{|l|}{ Women } \\
\hline Lung & 3 & 0.1 & 30 & $5.4-74.6$ & 0 & 0.6 & 0 & $0-1.7$ \\
\hline Colon and rectosigmoid & 4 & 0.4 & 10 & $2.5-22.5$ & 5 & 1.6 & 3.1 & $1.0-6.5$ \\
\hline Breast & 3 & 0.6 & 5 & $0.9-12.4$ & 3 & 2.9 & 1.0 & $0.2-2.6$ \\
\hline Unknown primary & 5 & 0.1 & 50 & $15.2-104.7$ & 2 & 0.6 & 3.3 & $0.3-9.7$ \\
\hline Pancreas & 4 & 0.1 & 40 & $10-90$ & 2 & 0.4 & 5.0 & $0.4-14.6$ \\
\hline Stomach & 2 & 0.1 & 20 & $1.7-58.3$ & 0 & 0.7 & 0 & $0-1.4$ \\
\hline Bladder & 0 & 0.1 & 0 & $0-40$ & 1 & 0.29 & 3.5 & $0-13.8$ \\
\hline
\end{tabular}




\subsection{Standardised morbidity ratio}

Cumulative follow-up of all 1464 patients during this selected period (1991-1998) was 3060 person-years with a median follow-up of 1.3 years (range $0-7$ years) for all patients, and a median follow-up of 7.4 years (range 10 months to 11 years) for those still alive. Cumulative follow-up (measuring the time interval between the date of diagnosis of the M-proteinaemia and the date of diagnosis of the solid tumour) for the Solid tumour group was 24 person-years (median less than 1 day, range 0-2.8 years). In conclusion, most solid tumours were diagnosed simultaneously with the detection of the M-protein (median interval between both diagnoses less than one day, see above). In the first year after the detection of the M-protein, SMR for nearly all solid tumours showed an increased risk (range 0-50). However, all declined sharply or normalised during the subsequent follow-up years (Table 2).

\section{Discussion}

In this population-based registry on patients with newly diagnosed M-proteinaemia, we describe the largest series collected thus far of patients with both a solid tumour and a M-protein, but without any evidence of a co-existing haematological malignancy. Since 1928, investigators have reported an increased prevalence of solid tumours in patients with M-proteinaemia suggesting a paraneoplastic phenomenon. For comparison with our cohort, we selected only studies with more than 100 patients, with a description of the related malignancy including concise histopathology and information on the determination of the M-protein, and were left with 8 [1-8]. Identical to our series, nearly all solid tumours described were (adeno)carcinomas. M-proteins were mostly of the $\operatorname{IgG}$ isotype and levels (if investigated) were generally lower than $30 \mathrm{~g} / \mathrm{l}$.

The co-existing tumours in this M-protein database were manifest at the diagnosis of the M-protein in the large majority of patients. During follow-up, only a small additional number of solid tumours were detected. Kyle and colleagues observed the development of a second tumour in 15 of 241 MGUS-patients during a 20-35 year follow-up [14] and Pasqualetti and colleagues reported 31 out of 263 similar patients who died due to a solid tumour during a median follow-up of 11.5 years [15]. In contrast, in the only prospective study investigating the incidence of hematological and solid malignancies in patients with M-proteinaemia, Gregersen and colleagues did not observe an increased risk of solid tumours in 1229 patients during follow-up (mean 4.8 years, range $0-15.7$ years) [16]. Similar to our findings, the risk of developing a solid tumour was increased in the first year of follow-up, although this risk diminished thereafter [16].

Approaching the probable relationship between M-proteinaemia and cancer the other way around yielded no association either: in two cross-sectional studies, the prevalence of M-proteinaemia in patients with non-haematological tumours was not increased when compared with the prevalence in the general population $[17,18]$.

In conclusion, we did not observe differences in clinical characteristics between patients with 'M-proteinaemia only/MGUS' and patients with 'Solid tumour and M-proteinaemia'. There was no relationship between specific solid tumours and M-protein isotype nor did the serum level of the M-protein change after the anti-tumour therapy (although the number of patients was small in this analysis). Although risks for nearly all solid tumours found were initially elevated in patients with newly diagnosed M-proteinaemia, these decreased in the year after suggesting a diagnostic selection of patients rather than a causal role.

\section{Acknowledgements}

We are indebted to Mr. K.G. van der Ham at the Department of Clinical Pathology for his assistance with Fig. 1.

\section{References}

1. Creyssel R, Fine J-M, Morel P. Etude biochimique de quelques formes atypiques de dysprotéinémies. Rev Hematol 1959, 14, 238-249.

2. Osserman EF, Takatsuki K. Plasma cell myeloma: gamma globulin synthesis and structure. Medicine 1963, 42, 357-385

3. Hällén J. Discrete gammaglobulin (M-) components in serum. Clinical study of 150 subjects without myelomatosis. Acta Med Scand 1966, 462, 1-127.

4. Danon F, Clauvel JP, Seligmann M. Les 'paraprotéines' de type IgG et IgA en dehors de la maladie de Kahler. Rev Fr Etud Clin Biol 1967, 12, 681-701.

5. Pick AI, Yeshurun D, Schreibman S, Fleminger R, Kessler H. Monoclonal gammopathy in patients with epithelial tumors. Harefuah 1974, 86, 5-13.

6. Colls BM, Lorier MA. Immunocytoma, cancer, and other associations of monoclonal gammopathy: A review of 224 cases. $N Z$ Med J 1975, 82, 221-226.

7. Ameis A, Ko HS, Pruzanski W. M components-a review of 1242 cases. Can Med Assoc J 1976, 114, 889-895.

8. Bonomo L, Dammacco F, Miglietta A. Paraproteinemia and neoplasia. Ric Clin Lab 1985, 15, 99-104.

9. Ong F, Hermans J, Noordijk EM, et al. A population-based registry on paraproteinemia in The Netherlands. Comprehensive Cancer Centre West, Leiden, The Netherlands. Br J Haematol 1997, 99, 914-920.

10. Ong F, Hermans J, Noordijk EM, et al. Developing a populationbased registry for patients with paraproteinemias or multiple myeloma. J Clin Epidemiol 1997, 50, 909-915.

11. World Health Organisation (WHO). International Classification of Diseases for Oncology, 1st ed., Geneva, 1976. 
12. Visser O, Coebergh JWW, Schouten LJ, Dijck JAAM. Incidence of cancer in the Netherlands 1994 and idem 1997. Utrecht, Vereniging van Intergrale Kankercentra.

13. Vandenbroucke JP. A shortcut method for calculating the 95 per cent confidence interval of the standardized mortality ratio. Am J Epidemiol 1982, 115, 303-304.

14. Kyle RA. Benign monoclonal gammopathy - after 20-35 years of follow-up. Mayo Clin Proc 1993, 68, 26-36.

15. Pasqualetti P, Festuccia V, Collacciani A, Casale R. The natural history of monoclonal gammopathy of undetermined significance. A 5- to 20-year follow-up of 263 cases. Acta Haematol 1997, 97, 174-179.
16. Gregersen H, Mellemkjaer L, Salling IJ, Sorensen HT, Olsen JH, Pedersen JO, et al. Cancer risk in patients with monoclonal gammopathy of undetermined significance. Am J Hematol 2000, 63, 1-6.

17. Migliore PJ, Alexanian R. Monoclonal gammopathy in human neoplasia. Cancer 1968, 21, 1127-1131.

18. Talerman A, Haije WG. The frequency of M-components in sera of patients with solid malignant neoplasms. Br J Cancer 1973, 27, 276-282.

19. Goffinet DR, Warnke R, Dunnick NR, et al. Clinical and surgical (laparotomy) evaluation of patients with non-Hodgkin's lymphomas. Cancer Treat Rep 1977, 61, 981-992. 